\title{
Wikis - professores e estudantes criando diários virtuais para aprender Matemática
}

\author{
Fabiana Fattore Serres \\ Marcus Vinicius de Azevedo Basso \\ \{fabiana.serres,mbasso\} @ufrgs.br \\ Instituto de Matemática - Universidade Federal do Rio Grande do Sul (UFRGS) \\ Porto Alegre - RS - Brasil
}

\section{Resumo}

No presente artigo apresentamos uma investigação de possíveis contribuições do uso do ambiente virtual pbwiki na aprendizagem de matemática. Descrevemos a dinâmica do trabalho proposto para os estudantes do terceiro ano do Ensino Médio do Colégio de Aplicação da Universidade Federal do Rio Grande do Sul (CAp-UFRGS) via situações e desafios. Destacamos resultados parciais da análise, a partir dos registros dos estudantes e professores, acerca da importância do exercício de produção textual por parte dos estudantes, bem como do uso dos pbwikis como potencializador da interação e cooperação entre os estudantes e entre estudantes e professores, favorecendo a aprendizagem de matemática.

Palavras-chave: cooperação, wiki, aprendizagem, matemática

\section{Wikis - teachers and students creating virtual diaries for learn mathematics}

\begin{abstract}
In this article we present an investigation of possible contributions of the use of the pbwiki virtual environment in the mathematical learning. We describe this work's dynamic proposed to Colégio de Aplicação da Universidade Federal do Rio Grande do Sul (CAp-UFRGS) senior year of high school students through challenge situations. We emphasize partial results from the analysis, with basis on students and teachers registers, about the importance of textual production by the students, together with use of pbwikis as interaction an cooperation increasing between the students and between students and teachers, improving the mathematical learning.
\end{abstract}

Keywords: cooperation, wiki, learning, mathematics

\section{Introdução - o contexto de trabalho}

O Curso de Licenciatura em Matemática da Universidade Federal do Rio Grande do Sul (UFRGS) tem como proposta a formação de professores capazes de contribuir na melhoria do ensino e conseqüente aprendizagem de matemática. Para tanto propicia sólida formação de conhecimentos em matemática, capacidade na utilização da tecnologia informática no ensino de matemática, formação pedagógica articulada às questões específicas do ensino e aprendizagem de matemática e desenvolvimento de competências práticas durante o transcorrer do Curso. Fundamentada na Resolução 04/2004 estabelecida pelo Conselho de Ensino, Pesquisa e Extensão da UFRGS, esta proposta prima pela importância da indissociabilidade entre a formação da especialidade e a formação pedagógica, bem como, pela inclusão da pesquisa como eixo articulador entre a construção do conhecimento específico e a prática pedagógica. Reconhecendo essas práticas pedagógicas como fundamentais para a formação dos futuros professores de Matemática, o Curso de Licenciatura em Matemática do Instituto de Matemática da 
UFRGS (IM-UFRGS) realiza uma série de atividades de Extensão que aliam tratamento de conteúdos matemáticos, desenvolvimento de competências práticas e oportunidade para pesquisa em Educação Matemática.

Como parte desse conjunto de ações de extensão, desde o ano de 2000 o IMUFRGS, em parceria com o Colégio de Aplicação da UFRGS (CAp-UFRGS), desenvolve oficinas onde alunos da disciplina de Laboratório de Prática de Ensinoaprendizagem em Matemática do Curso de Licenciatura em Matemática têm a possibilidade de atuar como professores junto a estudantes dessa Escola. Tais ações têm propiciado, para além da parceria institucional, oportunidades de desenvolvimento de trabalhos colaborativos entre docentes da Escola e os futuros professores de Matemática. Uma dessas parcerias nasceu quando da implementação da ação de extensão Oficinas e Assessorias de Matemática, Interação Virtual e Robótica para prática de ensino-aprendizagem em Matemática, realizada nos anos de 2006 e 2007, na qual a licencianda Fabiana F. Serres e o docente do CAP-UFRGS, Prof. Luiz Mazzei, trabalharam juntos. No ano de 2008, essa parceria fortaleceu-se com o convite desse docente para que a licencianda colaborasse com o projeto de pesquisa "Além de números e operações - leitura e escrita como formas de aprender matemática", que procura verificar se uma aproximação com a leitura e a escrita dos estudantes sobre suas práticas nas aulas contribuem para a aprendizagem de matemática. Fruto dessa parceria nasce o trabalho colaborativo no qual, docentes, licenciandos em Matemática e estudantes do Ensino Médio do CAp-UFRGS utilizam diários virtuais para registrar e trocar idéias relativas à resolução de problemas de matemática, cuja descrição e primeiros resultados serão apresentados no presente artigo.

Na seção 2 apresentaremos o desenvolvimento e a discussão dos resultados segundo a aprendizagem de conteúdos e desenvolvimento de capacidade no ensino médio (Pozo, 2003) utilizando comunidades virtuais de aprendizagem (Alava, 2002; Basso, 2003); na seção 3 apresentaremos as conclusões provisórias e as perspectivas para a continuidade da investigação iniciada com o presente estudo.

\section{Desenvolvimento e discussão dos resultados}

Inserido no contexto do projeto de pesquisa "Além de números e operações leitura e escrita como formas de aprender matemática" (Mazzei, 2008) e como parte da monografia "Recursos Digitais de Comunicação na aprendizagem de Matemática" (Serres, 2008), a partir de março de 2008 e até o presente momento, estamos desenvolvendo um trabalho com diários virtuais com as turmas do terceiro ano do CApUFRGS. Estreitamente relacionada com a constatação que a existência de salas de aulas com 30 ou 40 estudantes geram dificuldades para o professor atender cada aluno de um de modo qualificado bem como dificulta o acompanhamento e a evolução de cada estudante, levantamos as seguintes questões:

1. Poderíamos criar um canal de comunicação diferenciado que:

- para o professor, trouxesse informações sobre como os alunos estão compreendendo os conteúdos;

- para os estudantes, propiciasse condições de aprendizagem de conteúdos e o desenvolvimento de capacidades ao mesmo tempo em que ocorresse um atendimento individualizado?

2. Como?

Para responder a esses questionamentos, procuramos investigar a contribuição de ambientes virtuais na aprendizagem de Matemática bem como aspectos relacionados com as questões envolvendo aprendizagem em matemática. 


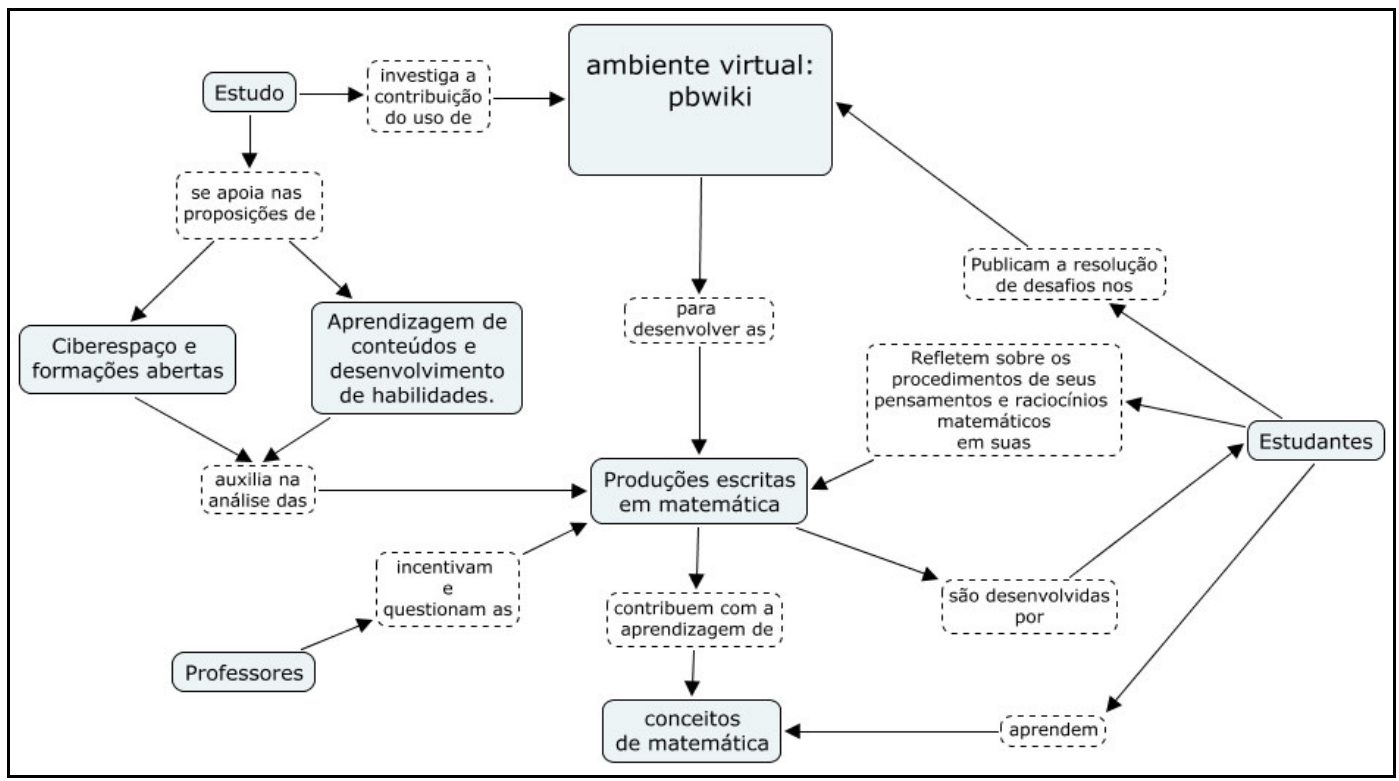

Figura 1 - Esquema da proposta de trabalho para o desenvolvimento do estudo

A primeira geração da internet, chamada web 1.0 tinha como principal objetivo a disponibilização da maior quantidade de informação possível a todos os usuários com transmissão de informação de "um para muitos". Com o surgimento da web 2.0 este modelo torna-se mais democrático e mais acessível aos usuários, tendo como principal objetivo transformar a rede em um meio social de contribuição, ou seja, um modelo de interação de "muitos para muitos" (Balbino, 2008).

Imbuídos deste espírito escolhemos os pbwikis como ferramenta para desenvolver este trabalho. Pbwikis são sites na web que permitem o trabalho colaborativo. São fáceis de usar permitindo uma edição rápida direto em um navegador de internet como se fosse um simples editor de texto. Deste modo qualquer um pode acrescentar, alterar ou apagar o conteúdo, ainda que este conteúdo não seja de sua autoria. Os pbwikis permitem interação e colaboração entre professor-aluno e entre aluno-aluno e possuem histórico de modificações que permite ao professor avaliar a evolução dos registros dos alunos. O objetivo deste trabalho era criar um espaço social de comunicação e de trabalho em grupo. Um espaço que permitisse ao estudante aprender a aprender, sendo co-responsável pelo próprio percurso de formação, com ênfase na aprendizagem de conceitos de matemática.

Criamos então um diário para cada estudante e para cada professor com o mesmo usuário e senha de modo que cada um teria acesso a todos os diários. Incentivamos os estudantes a transformar o seu pbwiki em um espaço pessoal a fim de criar condições de comunicação entre eles que não se restringisse apenas aos desafios propostos pelos professores.

A idéia do trabalho era publicarmos desafios que os estudantes resolveriam e publicariam no seu pbwiki. Procuramos selecionar atividades que favorecessem a descrição do processo de solução mais do que apresentar apenas os resultados dos desafios, pois nosso objetivo era que os estudantes refletissem sobre seus pensamentos e raciocínios matemáticos.

Como primeiro desafio trabalhamos com o raciocínio combinatório que era o conteúdo visto em aula naquele momento. 
Palíndromos são palavras que podem ser lidas da mesma maneira da esquerda para a direita e da direita para a esquerda. Por exemplo OMO, OVO, RENNER, ANA, a frase clássica SOCORRAM-ME SUBI NO ONIBUS EM MARROCOS. Existem números que também são palíndromos, podem ser lidos em qualquer sentido: Por exemplo: 171, $22,1001,8778$, etc.

Determina quantos números de 5 algarismos são palíndromos, explicando tuas idéias.

Desafio 1 - http://diariomatcap.pbwiki.com/Desafios

Queríamos também neste desafio que os estudantes se familiarizassem com a ferramenta pbwiki e começassem a interagir com os colegas.

Abaixo destacamos as respostas de dois alunos:

Pois é, um número palíndromo de 5 algarismos, bom... temos 5 espaços *****. No primeiro podemos colocar qualquer número de um a nove, sem o zero pois é um número de cinco algarismos (9.*****). Já que é um palíndromo (dããã) o último algarismo tem que ser igual ao primeiro, então temos apenas uma possibilidade para o algarismo final (9.****1). Exercemos a mesma relação entre o segundo e o penúltimo algarismo do número, apenas acrescentamos o zero como possibilidade (9.10*.1.1) e o algarismo do meio pode ser qualquer algarismo, de zero a nove, então temos mais 10 possibilidades $(9.10 .10 .1 .1)$. $=\mathrm{D}$ http://allanmartiny.pbwiki.com/

Constatamos que o relato é feito de modo descontraído, o que no nosso entendimento, reflete a orientação e proposta do trabalho, que consistia em criar um ambiente de total liberdade de expressão das idéias dos estudantes. Este aluno não somente descreve o raciocínio desenvolvido para resolver o desafio proposto, como também demonstra compreender este algoritmo na medida em que o explica.

Já na fala de Bruna, apresentada a seguir, observamos sua manifesta preocupação em não copiar o desafio dos colegas demonstrando o sentimento de responsabilidade acerca de sua própria formação.

ta eu consegui, só que eu ja tinha visto a resposta antes de responder pq eu entrei no diário dos coléguinhas antes de fazer o desafio. então não teve graça! http://brunaourique.pbwiki.com/

No segundo desafio procuramos algo interessante, que os estudantes tivessem de descrever o processo de resolução e não tivesse uma resposta única.

Este desafio consistia em ajudar os três canibais e os três missionários a passarem para o outro lado do rio com o cuidado de nunca deixar mais canibais do que missionários na mesma margem do rio.

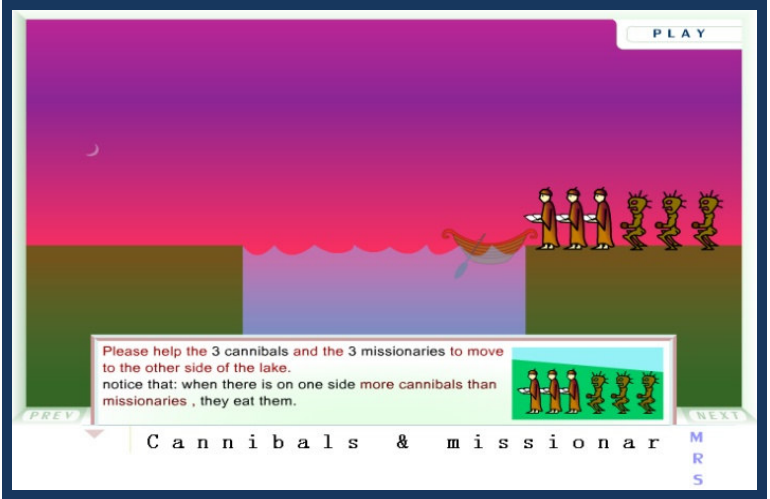

Figura 2 - Desafio 2 -

http://www.plastelina.net/game2.html

Os alunos precisavam descrever o processo de resolução no seu pbwiki. Além disso, os estudantes deveriam fazer comentários sobre a resolução de dois colegas da sua turma que vinham logo abaixo deles na lista dos pbwikis. Queríamos com isso que 
além de interação social surgisse interação do ponto de vista da troca de idéias em relação aos conhecimentos de matemática.

Observa-se na resposta abaixo a empolgação da aluna ao resolver o desafio:

Muito interessante o desafio, isso que realmente é um desafio. Beijo (16/06/2008 23:05)

Depois de algumas tentativas (não foram muitas mesmo), consegui fazer o desafio, nossa, pensei muito. Aqui está a resolução :

"Ponho dois canibais dentro da arca, vou até o lado esquerdo do rio, mas deixo apenas um canibal, volto com um canibal na arca e pego o último canibal no lado direito, vou até o lado esquerdo e deixo este canibal também lá, volto para o lado direito com apenas um canibal, no lado direito, tiro o canibal e coloco dois missionários, vou ao lado esquerdo e deixo apenas um missionário, mas ponho um canibal na arca, volto então para o lado direito com um missionário e um canibal (como casais), deixo o canibal e ponho o último missionário, levo-o para o lado esquerdo, deixo os dois missionários no lado esquerdo - sendo que no direito tem dois canibais - volto para o lado direito com apenas um canibal na arca - no lado esquerdo agora existem três missionários - no lado direito ponho mais um canibal na arca, vou para o lado esquerdo e deixo um canibal - agora, no lado esquerdo existem três missionários e um canibal - volto com um canibal na arca para o lado direito, pego o último canibal e o ponho no lado esquerdo - agora existem três missionários e dois canibais - tiro o último canibal da arca e TCHANANANANANAM!!!!! Agora os três missionários e os três canibais estão no lado esquerdo." http://fabianesilva.pbwiki.com/

A Fabiane além de descrever o processo de resolução seguido por ela publicou uma imagem que ela chamou de "foto da minha vitória".

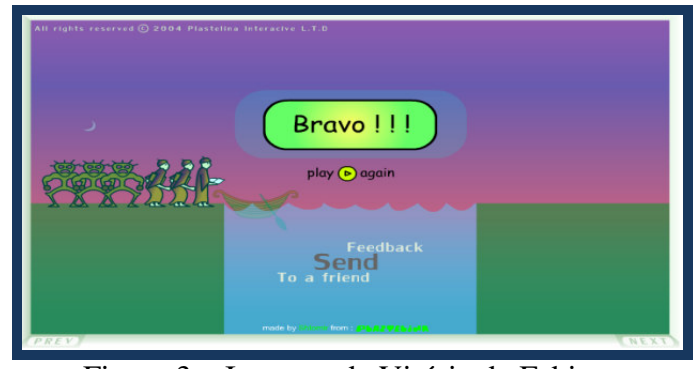

Figura 3 - Imagem da Vitória da Fabiane

Os estudantes ficaram empolgados com o desafio e curiosos quanto à resolução dos colegas e acabaram comentando além dos dois pbwikis recomendados, aumentando a interação entre eles. No extrato abaixo do pbwiki do Luiz Felipe percebemos esta interação:

eu fui comentar no diario do marcos e nao entendi o que ele havia escrito, entao eu pensei em um quadro pra explicar melhor.... eu decidir colocar fotos...

http://turma113.multiply.com/photos/album/4/desafio

$=\mathrm{D}$

ILHA DA ESQUERDA | BARCO | ILHA DA DIREITA

\begin{tabular}{l|l|l}
0 & 0 & $3 \mathrm{~m}+3 \mathrm{c}$
\end{tabular}

\begin{tabular}{l|l|l}
$1 \mathrm{c}$ & $1 \mathrm{~m}$ & $2 \mathrm{~m}+2 \mathrm{c}$
\end{tabular}

\begin{tabular}{l|l|l}
$1 \mathrm{c}$ & $2 \mathrm{c}$ & $3 \mathrm{~m}$
\end{tabular}

\begin{tabular}{l|l|l}
$2 \mathrm{c}$ & $1 \mathrm{c}$ & $3 \mathrm{~m}$
\end{tabular}

$1 \mathrm{c}+1 \mathrm{~m} \quad|1 \mathrm{c}+1 \mathrm{~m} \quad| 1 \mathrm{c}+1 \mathrm{~m}$

$1 \mathrm{c}+1 \mathrm{~m} \quad \mid 2 \mathrm{~m} \quad$ | $2 \mathrm{c}$

$3 \mathrm{~m} \quad \mid 1 \mathrm{c} \quad$ | $2 \mathrm{c}$

$3 m+1 c \quad|2 c \quad| 0$

$3 m+3 c \quad|0 \quad| 0$

Legendas: $\mathrm{C}=$ canibal e $\mathrm{M}=$ missionario

LUIZ FELIPE - http://luizterra.pbwiki.com/ 
Luiz Felipe diz que não entendeu o que o colega escreveu e então tem a idéia de construir uma tabela para explicar o seu próprio processo de resolução do desafio. Ele cria uma simbologia própria para representar o problema e, além disso, captura a imagem da tela a cada passo resolvido do desafio e as organiza como se estivessem em um álbum de fotos (http://turma113.multiply.com/photos/album/4/desafio).

$\mathrm{Na}$ terceira atividade os alunos precisavam primeiro resolver o desafio para encontrar a senha que permitia a abertura de um arquivo Excel, depois explicar como pensaram para resolver o problema proposto no arquivo e publicar em seu pbwiki. Desta maneira não era possível ver a resposta dos colegas antes de resolver o desafio.

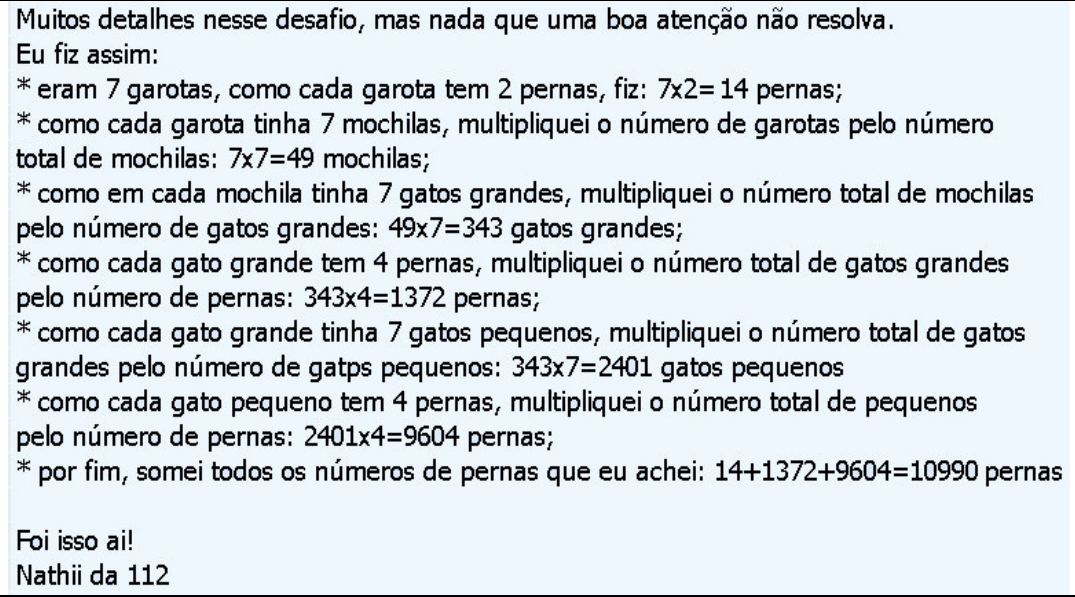

Esta aluna além de descrever o procedimento de resolução do desafio proposto fez uma representação gráfica dos conjuntos envolvidos para poder entendê-los melhor e então conseguir contar seus elementos. Foi uma maneira que ela encontrou de mostrar para os colegas e professores o seu raciocínio.

Neste desafio, como eles não podiam ver a resolução dos colegas antes de resolver, houve um aumento considerável das interações aluno-professor.

Como podemos ver no extrato de e-mail abaixo onde a aluna procura ajuda para solucionar o desafio.

Soraaa...não consegui fazer o desafio 3 , tem alguma dica que tu pode me dar??

Beijos

Oi Marthielle

Dicas para o desafio 3: Faz um esquema como um desenho assim: de uma garota saem 7 flechinhas (são as mochilas) de cada mochila sai 7 flechinhas (são os gatos grandes) de cada gato grande saem 7 flechinhas (são os gatinhos) daí conta as pernas: 4 para cada gato e duas para cada garota. Se não conseguir grita aí que eu dou mais dicas.

Bjo Profa Fabi

Tah! eu to na minha tia, dai vou fazer este em casa! ;D

Mas os que eu consegui fazer estão publicados já!

beijos! Obrigadaaa

Extrato de um diálogo com uma aluna via e-mail

No diálogo acima se pode observar novamente a descontração entre os participantes do trabalho. Esse se constituiu em um dos aspectos marcantes durante todo o trabalho: os alunos trabalharam divertindo-se. Alguns alunos tiveram dificuldade em publicar o arquivo Excel com o relato do seu desafio no seu pbwiki como no extrato abaixo de uma conversa com o aluno Marcos via MSN. 


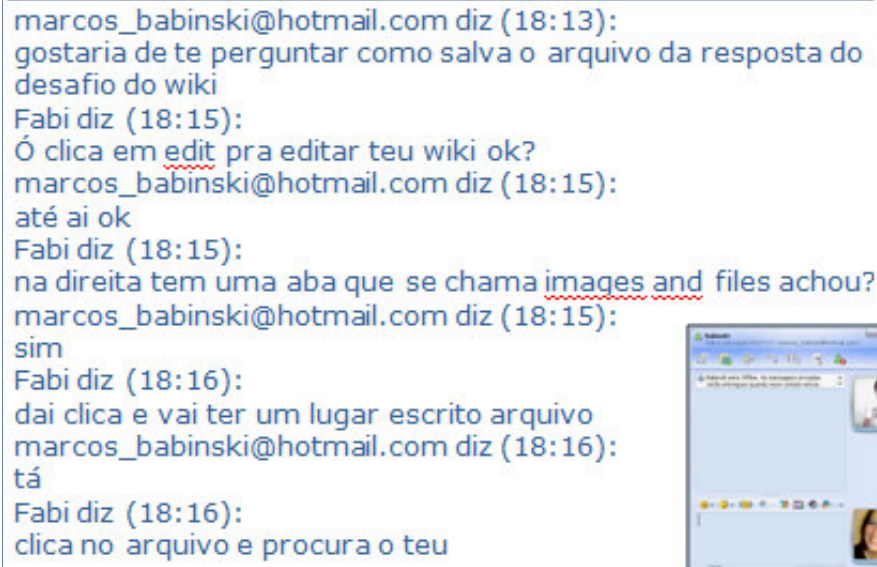

Figura 4 - Extrato de uma conversa via MSN com um aluno

A proposta seguinte dos professores envolvia conceitos de geometria, assunto que eles estavam aprendendo em sala de aula. Para isso, foi utilizado o objeto digital de aprendizagem denominado simetrizador, desenvolvido por dois estudantes do Curso de Licenciatura em Matemática (IM-UFRGS), Gabriel Flores e Tamiris Duarte.

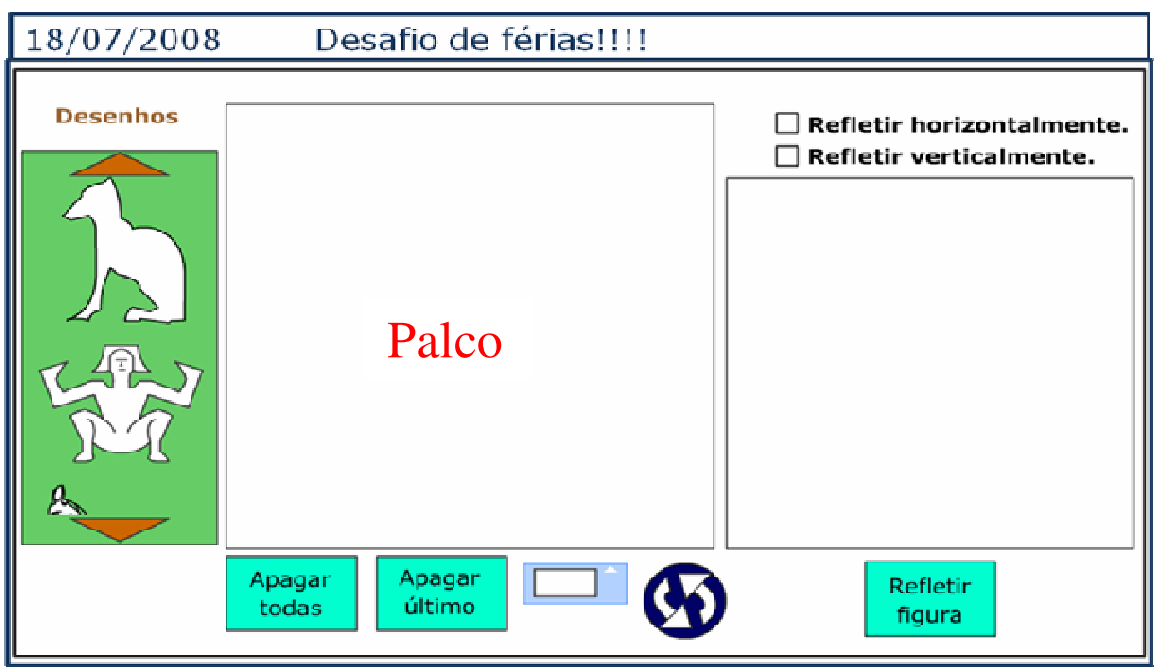

Figura 5 - Objeto digital de aprendizagem - Simetrizador

No objeto, inspirado nas obras de Escher, o estudante tem como objetivo preencher, sem lacunas, o palco em branco com as figuras da esquerda do simetrizador. Algumas questões acompanhavam este desafio para que os alunos pensassem sobre simetria e geometria:

1) É possível preencher o palco usando apenas figuras iguais? (Explique se são iguais, se têm semelhanças, se podem ser obtidas umas a partir das outras, etc.).

2) É possível combinar mais de um tipo de figura e ainda assim preencher por completo o palco? Como você faria para conseguir isto?

3) Dê um exemplo de figura geométrica com a qual seria possível preencher, sem lacunas, o palco em branco. estudantes.

A seguir destacamos as imagens criadas e os comentários registrados por duas 


\section{.}

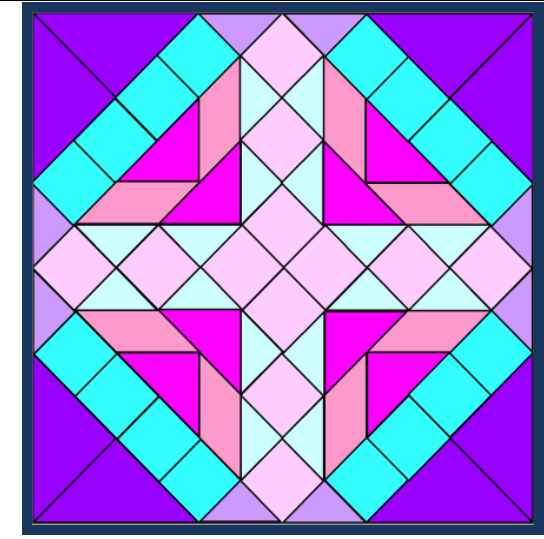

Figura 6 - Imagem criada pela Marthielle Não sei se é possível preencher com a mesma imagem, mas com imagens parecidas sim! Eu formei com as mesmas imagens, mas uma o oposto da outra e com cores diferentes deu um efeito tri. http://marthiellerocha.pbwiki.com/

O último desafio publicado consiste em diários coletivos. Cada turma possui um diário e juntos relatam o que estão aprendendo em aula com suas próprias palavras.

Oi pessoal

O novo desafio é coletivo. Isso mesmo!!!

Tem 3 novos pbwikis: $\underline{111}, \underline{112}$ e $\underline{113}$.

A idéia é vocês construírem os novos pbwikis juntos, isto é, todo mundo publicando junto. Publicando o que? Cada wiki vai ter o registro do que vocês estão aprendendo em sala de aula. Regra única: tem de ser escrito com as palavras de vocês, não vale cópia.

Também podem usar o espaço para pedir socorro, quem precisa pergunta e quem sabe ajuda ok? bjo Profa Fabi

Abaixo destacamos um extrato do diário coletivo da turma112:

Oi pessoal

A idéia é vocês relatarem neste espaço o que estão aprendendo em aula. Mas não basta dizer qual conteúdo estão aprendendo. É para explicar como vocês entenderam. Vou dar um exemplo. Não basta dizer: Aprendemos a calcular a distância entre dois pontos. É preciso explicar como se calcula a distância entre dois pontos e porque ok? by Profa Fabi

Poxa, é mais difícil do que eu pensei..

tá, acabamos de ver geometria analítica com a circunferência. Para saber se uma equação é uma circunferência, ela precisa seguir o modelo: $(a-x)(b-y)=r^{2}$, onde as coordenadas do centro são os valores de $\mathrm{x}$ e y, e o seu diâmetro é o raio ao quadrado. Bom, é isso! :D

Beeeijos Nathii

Oi Natália!!

Escrever é difícil mesmo... Quando nos dizem o que fazer, com números, vamos lá e fazemos, não é?! Mas ter de explicar com palavras é bem mais complicado. Temos de ter os conceitos claros em nossa mente.

Agora vamos pensar juntos... O diâmetro de uma circunferência é o seu raio ao quadrado?

By Prof ${ }^{a}$ Fran.

Ah é verdade, cometi um GRANDE engano. $=\mathrm{D}$

$O$ raio é a metade do diâmetro. Porque assim: se o diâmetro é 10, o raio é 5 !

e do jeito que eu falei, se elevasse o 5 ao quadrado $\left(5^{2}\right)$ daria 25 e não 10.

Beeijo pessoal

Nathi (14.10.2008)

V. 6 No 2, Dezembro, 2008 
Os diálogos acima envolvem duas professoras e uma aluna. Na primeira fala, a professora Fabi expressa sua expectativa quanto à produção dos alunos no diário coletivo. Na segunda fala, a aluna registra que estão aprendendo sobre a equação da circunferência, mas escreve que o diâmetro é o raio ao quadrado. Essa incorreção não será abordada pela Professora Franciele simplesmente apontando o erro. Aqui a estratégia manifesta é a de incentivar a aluna a escrever e sugerindo que ambas pensem juntas sobre o raio da circunferência. Essa conduta por parte da professora estabelece a condição de um diálogo que permitirá que a aluna reflita sobre o conceito matemático envolvido e o corrija logo a seguir, como se constata pela última fala destacada no extrato.

A opinião dos professores do CAp-UFRGS tem grande relevância neste trabalho e destacamos a seguir um trecho da avaliação desse trabalho, realizado pelo professor Sandro.

"Ter a oportunidade de observar como cada aluno tenta explicar, argumentar, descrever, ter idéias diferentes sobre o mesmo assunto e como se depara com suas dificuldades fez com que o meu processo de avaliação também mudasse... o trabalho além de fornecer um ambiente de aprendizagem diferente do convencional, proporciona uma interação aluno-aluno e alunoprofessor que antes não conhecia, e espero que eu possa a partir dessas observações reelaborar o meu conceito de aprendizagem buscando novas alternativas de entendimento desse processo."

Pela fala deste professor percebemos que a parceria entre professoreslicenciandos e professores da Escola fortalece a troca de idéias envolvendo questões de ensino-aprendizagem de Matemática e a criação de propostas de ensino e em contrapartida os estudantes da Escola são beneficiados pela criação de propostas que visam contribuir para a aprendizagem de Matemática e retornam com informações para o grupo de professores e professores-licenciandos.

Este é um extrato de um registro de um aluno da turma 113:

“...toda atividade pedagógica fora de sala de aula contribui para que a prática, no que se refere à resolução de exercícios, somente traga benefícios. Com os Wikis, os alunos têm oportunidade de organizar o seu espaço virtual, podendo interagir com os colegas num espaço diferente da sala de aula. O conhecimento vem, de uma forma distinta da convencional, tanto para a própria matemática quanto o referente ao uso do computador.“

\section{Avaliação do professor Luiz Mazzei sobre o trabalho:}

"O trabalho com os wikis possibilita aos alunos desenvolverem autonomia e a capacidade de buscar soluções aos problemas apresentados. Estimula também a interação e a cooperação entre eles na busca pela solução tornando assim a matemática como uma atividade social."

E da professora Franciele:

"Acredito que uma boa maneira de avaliar se aprendemos alguma coisa é tentando explicá-la para outra pessoa. Com o wiki os alunos têm a oportunidade de elaborar explicações de coisas que aprenderam em aula e de argumentar em cima de explicações de colegas, o que movimenta os conceitos envolvidos. Eu, como professora, interfiro na discussão colocando questões, e assim, consigo visualizar possíveis falhas ou conceitos não muito claros ainda para meus alunos."

\section{Conclusões e Perspectivas}

A característica de priorizar que os estudantes descrevessem os procedimentos de resolução dos desafios neste trabalho permitiu que eles refletissem sobre os seus próprios procedimentos e raciocínios matemáticos. Essas reflexões, por sua vez, criaram as possibilidades e condições para que esses estudantes modificassem a maneira como enfrentam as tarefas e os desafios, ou seja, que a cada desafio vencido eles reelaborassem sua maneira de aprender a aprender. (Pozo, 2003) 
Considerando que a interatividade é um fator que influencia a aprendizagem (Alava, 2002) e que as propostas de trabalho com o uso de pbwikis favoreceram as interações e trocas de informações envolvendo conceitos de Matemática tanto entre alunos-alunos quanto entre professores-alunos, constatamos que os estudantes participantes desse trabalho apresentaram no decorrer do ano letivo, uma melhora na escrita envolvendo os conceitos de Matemática. Constatamos, também via análise dos registros escritos dos estudantes, eles demonstraram compreender conceitos de Matemática presentes nos desafios e situações didáticas e igualmente relevantes, apresentaram crescimento em termos de aprendizagem de matemática.

Trabalhar em equipe, respeitando as idéias e posições dos colegas, de forma cooperativa possibilitou ao estudante desenvolver novas estratégias e atitudes autônomas, como fazer-se perguntas e tirar suas próprias conclusões formando seu ponto de vista, influenciando suas atitudes futuras e contribuindo para a aprendizagem de matemática. (Pozo, 2003)

Devido à riqueza de possibilidades desta proposta, além de pretendermos dar prosseguimento em 2009 à sua implementação com alunos das demais turmas do Ensino Fundamental e Médio do CAp-UFRGS, é intenção prosseguirmos o trabalho de investigação movidos por novas interrogações surgidas durante a atual pesquisa.

1 - Como os alunos trabalham cooperativamente usando os pbwikis?

2 - Quais são os limites e quais são os benefícios desta proposta para o fazer pedagógico do professor e para a aprendizagem dos estudantes?

3 - Que possibilidades são oferecidas pelos pbwikis que não conseguiríamos só com o trabalho em sala de aula?

4 - Quais são as diferenças dos conceitos de aprender e ensinar no trabalho com os pbwikis em relação ao trabalho em sala de aula?

No atual estágio desse estudo, com base nos dados obtidos, concluímos que a proposta apresentada se mostrou favorável a apropriação de novos conceitos, capacidades e atitudes por parte dos alunos, contribuindo, portanto, para a aprendizagem de matemática. Também foi possível constatar que esse trabalho tem um impacto sobre o trabalho dos docentes na medida em que os processos de interação estabelecidos entre esses e seus alunos foi potencializado pelos usos dos recursos digitais de comunicação na modalidade ora apresentada.

\section{Referências}

ALAVA, Séraphin. Ciberespaço e formações abertas. Porto Alegre: Artmed, 2002.

BALBINO, Jaime. Num mundo wiki, uma escola idem - Parte I. Disponível em: <http://www.dicas1.com.br/educacao_tecnologia/print/educacao_tecnologia_20070115.html> Acesso em: 15/10/2008.

BASSO, Marcus V. de A. Espaços de aprendizagem em rede: novas orientações na formação de professores de matemática. Tese. Universidade Federal do Rio Grande do Sul. Programa de PósGraduação em Informática na Educação, Porto Alegre, 2003. Disponível em: $<$ http://mathema.psico.ufrgs.br/tese_m/ > Acesso em: 15/10/2008.

BOTTENTUIT, João Batista; COUTINHO, Clara. Blog e wiki: os futuros professores e as ferramentas da Web $\quad \mathbf{2 . 0}$ Disponível em: $<$ https://repositorium.sdum.uminho.pt/bitstream/1822/7358/1/Com\%20SIIE.pdf> Acesso em: 15/10/2008. MAZZEI, Luiz. Além de números e operações - leitura e escrita como formas de aprender matemática. Disponível

em: <http://www1.ufrgs.br/pesquisa/forms/form_dadosProjetoPesquisa.php?Cod=13150> Acesso em: 15/10/2008. POZO, Juan Ignacio. Aprendizagem de conteúdos e desenvolvimento de capacidades no ensino médio. In: COLL, César. Psicologia da aprendizagem no ensino médio. Porto alegre: ARTMED, 2003.

SANTOS, Nilton. A revanche do hipertexto. Disponível em: <http://www.datagramazero.org.br/abr08/Art_03.htm> Acesso em: 15/10/2008.

UNIVERSIDADE FEDERAL DO RIO GRANDE DO SUL - INSTITUTO DE MATEMÁTICA. Projeto Pedagógico dos Cursos de Licenciatura em Matemática e Licenciatura em Matemática-noturna. Disponível em: <http://euler.mat.ufrgs.br/ comgradmat/resolucoes/licmat_projeto.pdf> Acesso em: 01/11/2008. V. 6 No 2, Dezembro, 2008 